\title{
Variability in the maximum height of the ionospheric F2-layer over Millstone Hill (September 1998-March 2000); influence from below and above
}

\author{
D. Pancheva ${ }^{1,2}$, N. Mitchell ${ }^{2}$, R. R. Clark ${ }^{3}$, J. Drobjeva ${ }^{4,}$, , and J. Lastovicka ${ }^{4}$ \\ ${ }^{1}$ Physics Department, University of Wales, Aberystwyth, UK \\ ${ }^{2}$ Department of Electronic \& Electrical Engineering, University of Bath, Bath, UK \\ ${ }^{3}$ Electrical and Computer Engineering Department, University of NH, USA \\ ${ }^{4}$ Institute of Atmospheric Physics, Prague, Czech Republic \\ * present address: Institute of the Ionosphere, Almaty, Kazakhstan
}

Received: 4 February 2002 - Revised: 7 May 2002 - Accepted: 16 May 2002

\begin{abstract}
The basic aim of this 'case study' is to investigate the variability in the maximum height of the ionospheric F2layer, $h m \mathrm{~F} 2$, with periods of planetary waves (2-30 days), and to make an attempt to determine their origin. The hourly data of $h m \mathrm{~F} 2$ above Millstone Hill $\left(42.6^{\circ} \mathrm{N}, 71.5^{\circ} \mathrm{W}\right)$ during 01 September 1998 - 31 March 2000 were used for analysis. Three types of disturbances are studied in detail: (i) the 27day oscillations observed in the $h m \mathrm{~F} 2$ above Millstone Hill are generated by the geomagnetic activity and by the globalscale 27-day wave present in the zonal mesosphere/lower thermosphere (MLT) neutral wind. The time delay between the 27-day oscillation in the zonal wind and that in the $h m \mathrm{~F} 2$ is found to be 5-6 days, while between the 27-day oscillation in the geomagnetic activity and that in the $h m \mathrm{~F} 2$ is found to be $0.8-1$ day; (ii) the 16-day oscillation in the $h m \mathrm{~F} 2$ observed during summer 1999 is probably generated by the global scale 16-day modulation of the semidiurnal tide observed in the MLT region during PSMOS campaign in June-August. We found that if the modulated semidiurnal tide mediates the planetary wave signature in the ionosphere, this planetary wave oscillation has to be best expressed in the amplitude and in the phase of the 12-h periodicity of the ionosphere; and (iii) the third type of disturbances studied is the quasi-2day activity in the $h m \mathrm{~F} 2$ that increases during geomagnetic disturbances. The strong pseudo diurnal periodicities generated during the geomagnetic storms can interact between each other and produce the quasi-2-day oscillations in the ionosphere.
\end{abstract}

Key words. Ionosphere (ionosphere-atmosphere interactions; ionosphere-magnetoshpere interactions; wave propagation

Correspondence to: D. Pancheva (ddp@aber.ac.uk)

\section{Introduction}

The physics of the ionosphere-thermosphere system is complicated and the reasons responsible for this could be summarised as follows: (i) the variability of the external sources that drive the system; (ii) the internal interactions that occur in this system, and (iii) the interactions with the magnetosphere above and with the middle atmosphere below. All these factors set the pattern for the ionospheric variability and can be defined respectively as: solar, magnetospheric and meteorological influences.

Recently, Forbes et al. (2000) examined hourly foF2 data from over 100 ionosonde stations during 1976-1989 to quantify to what degree the observed variability in the ionosphere F-region is attributed to the above mentioned sources. They found that under quiet geomagnetic condition the variability of the $N_{\max }$, due to the meteorological influences, is $\sim 25$ $35 \%$ at periods of a few hours to $1-2$ days and $\sim 15-20 \%$ at periods of planetary waves (2-30 days). Rishbeth and Mendillo (2001) used ionosonde data from thirteen stations to study the day-to-day variability of the peak F2-layer electron density, $N m \mathrm{~F} 2$, versus local time, season and solar cycle. They separated day and night variability and found that for years of medium solar activity (solar radio flux approximately 140 units), the daily fluctuations of $N m \mathrm{~F} 2$ have standard deviation of $20 \%$ by day and $33 \%$ by night. Geomagnetic activity is accepted by the authors as a major cause of this variability, though 'meteorological' causes transmitted from lower levels may make a comparable contribution. Apostolov et al. (1998) found the planetary wave type oscillation contribution to be highest near the summer solstice and lowest near the winter solstice. Rishbeth and Mendillo (2001) also found differences between the solstices: in general, variability at night is greater in winter than in summer, but by day the variability is greater in December than in June 
in both hemispheres. The same authors found also that variability is somewhat greater at subauroral and equatorial latitudes than at midlatitudes.

The so-called meteorological influences on the ionosphere and thermosphere are related to the processes originating in the lower atmosphere through which energy and momentum is transmitted from below to the upper atmosphere. The energy and momentum deposition occurs mainly as the result of upward propagating tides, planetary waves (PW) and gravity waves. These waves grow exponentially up to altitudes around $80-120 \mathrm{~km}$, where dissipation becomes important, or where they become convectively unstable and break. This breakdown can cause turbulence and contribute to heating and acceleration of the mean flow. The rate of dissipation determines how much of the wave energy can reach the thermosphere altitudes. Miyahara and Wu (1989) indicated that in the thermosphere the upward propagating semidiurnal tide provides most of the momentum forcing, as the contribution of the diurnal tide occurs mainly below $120 \mathrm{~km}$. Recently the capabilities of the global-scale wave model (GSWM) (Hagan et al., 1995, 1999) were extended to include migrating thermospheric solar tides (Hagan et al., 2001). It was shown that in situ thermospheric semidiurnal tide is weaker than the diurnal tide. The upward propagating tide dominates the semidiurnal response throughout the thermosphere, while in situ forcing accounts for most of the diurnal response. The dynamo electric fields, which through the plasma drift serve to redistribute ionospheric plasma, are produced to a large extent in the ionospheric E-region, and tides propagating up from the lower atmosphere are involved in this process (Forbes, 1996).

Solar UV radiation, which is a major source of energy and ionisation, varies with periods of years (for example, the 11year solar cycle) and days (such as the well known quasi-27day solar rotation period). The solar flux generates variations in neutral composition, neutral temperatures, conductivities and neutral winds that influence the ionosphere plasma densities. Forbes et al. (2000) found that the major source of ionospheric variability is due to long-period solar flux changes, i.e. the 11-year solar cycle. The annual and semiannual variations (related to the seasonal solar zenith angle dependence) represent small variability, compared to long-term solar changes. The variability associated with day-to-day solar flux variations, including the 27-day solar rotation, is similar to the annual and semiannual variations. The presence of the 27-day oscillation in the ionospheric variability is a natural event, however Pancheva et al. (1991) found that this oscillation, observed in the lower ionosphere, can be from direct solar origin during high solar activity and of meteorological origin, mainly in winter and equinoxes during low solar activity. Luo et al. (2001) investigated the climatological and statistical characteristics of the long-period (20-40-day) oscillations in the mesosphere and lower thermosphere (MLT) neutral winds above Saskatoon during 1980-1999 and found that these oscillations could be related to the solar rotational period, however, only in some cases. Therefore, the observed long-period (20-30-day) oscillations in the ionospheric F- region plasma variability could be partly of non-solar origin.

Magnetospheric forcing on the ionosphere-thermosphere system acts mainly poleward of $50^{\circ}$ geomagnetic latitude and it depends on the level of geomagnetic activity. The ionospheric response to geomagnetic storms is known as the 'ionospheric storm'. The storm source is characterized usually by an increase in the magnetospheric convection electric field (Foster et al., 1986) and in the cross-polar cap potential, as well as an increase in energetic particle precipitation (Fuller-Rowell and Evans, 1987). The ionospheric variability is associated mainly with the changes in the neutral winds, neutral composition and structure, as well as with the generation of the gravity waves that propagate toward the equator. The storm effects in the ionospheric F-region have been widely discussed (Prölss, 1995) and some modelling results have shed light on the dynamic interaction between the thermosphere and ionosphere in their response to geomagnetic storms (Fuller-Rowell et al., 1994; 2000).

The basic aim of this work is to study the variability in the maximum height of the ionospheric F2-layer, $h m \mathrm{~F} 2$, with periods of PWs (2-30 days), and to make an attempt to determine their origin. We used the ionospheric parameter $h m \mathrm{~F} 2$ as it is closely related to the vertical plasma drift and in this way, it is more sensitive to the influence of dynamics. The main problems discussed in this "case-study" are: (i) how to separate the 27-day response of the F-region generated by the solar rotation or geomagnetic variability from that generated by the neutral wind observed in the MLT region; (ii) how to distinguish the response of the F-region to the globalscale PW modulated semidiurnal tide observed in the MLT region, and (iii) why the amplitudes of the quasi-2-day oscillations observed in the ionospheric F-region increase during geomagnetic disturbances.

\section{Data set and method of analysis}

To study ionospheric variability we use hourly values of the real $h m \mathrm{~F} 2$ for the Millstone Hill station $\left(42.6^{\circ} \mathrm{N}, 71.5^{\circ} \mathrm{W}\right)$. The 15-min values of $h m \mathrm{~F} 2$ were downloaded from web site: http://www.digisonde. haystack. edu during the time interval 1 September 1998 - 31 March 2000, or full 19 months. The source of $h m \mathrm{~F} 2$ is a digisonde and data are obtained by automatic ionogram scaling with ARTIST (Reinisch, 1996). The gaps in the data did not exceed 8 hours and all gaps were approximated by cubic spline. Then hourly values of $h m \mathrm{~F} 2$ were picked out for analysis. To obtain information about the dynamical regime in the MLT region we used the hourly measurements of the neutral wind made by the meteor radar at Durham $\left(43.1^{\circ} \mathrm{N}, 70.9^{\circ} \mathrm{W}\right)$, which is situated very close to Millstone Hill. To characterize the geomagnetic activity a 3 -hourly $A_{p}$-index is used, while as a proxy of the solar activity we use the daily values of the solar radio flux F10.7.

The wavelet transform was used to investigate the changing composition of the planetary-wave field. This approach is becoming a favoured tool for analysing time series in which 
the standard time-stationary assumption does not hold. Decomposing the time series into time-frequency space, the wavelet transform is able to determine both the constituent frequencies and how those frequencies vary in time, producing a two-dimensional time-frequency image (Torrence and Compo, 1998). The analysis presented here used the continuous Morlet wavelet, which consists of a plane wave modulated by a Gaussian envelope. The Morlet wavelet was selected because of its simplicity and resemblance to the modulated planetary-wave "packets", which are frequently observed in the ionosphere and MLT region variability (Pancheva and Mukhtarov, 2000). In the following results, we present the wavelet coefficients as a function of period and time. The magnitude of the wavelet coefficient is related to the amplitude of the oscillation and provides a qualitative indication of the spectral composition of the wave field. Additional spectral information was gained by applying the high-resolution correloperiodogram analysis (Kopecky and Kuklin, 1971).

A refinement of this analysis is used to investigate any periodicities simultaneously present in two or more time series. In this particular case, we apply a cross-wavelet analysis, where the cross-wavelet power serves as an indication for the strength of the oscillations co-existing in both time series, and the argument describes the phase difference between them.

The bispectral analysis technique was applied to the time series of hourly data, in order to investigate the non-linear effects in the ionospheric F-region. The conventional "Fourier type" methods for bispectrum estimation can serve as reliable quantifiers of phase coupling, and therefore these techniques were used in investigating the non-linear interactions between waves in the atmosphere (Clark and Bergin, 1997; Beard at al., 1999; Pancheva, 2000). In the present work the magnitude-squared bispectrum is calculated from the hourly values of $h m \mathrm{~F} 2$. The computational procedure is described in detail by Pancheva (2000).

\section{Results}

Figure 1 shows the wavelet spectra of the solar radio flux F10.7, the geomagnetic $A_{p}$-index and the maximum height of the F2-layer over Millstone Hill in the period range 3-30 days. The thick dashed lines represent the cone-ofinfluence. For any given time all the periods above these lines are expected to suffer from edge effects. The thick contour lines represent 95\% confidence levels (Pancheva and Mukhtarov, 2000). The 3-hourly mean data are used in this wavelet analysis to reduce the noise of the time series from hourly values of $h m \mathrm{~F} 2$. This makes it easier to compare the 3-hourly mean $h m \mathrm{~F} 2$ with the 3 -hourly $A_{p}$-index. The longterm oscillations with periods longer than 3 months were removed (we study the difference between the row data and the 91-day running mean) from the time series under consideration before the wavelet spectra were generated. Looking at the significant long-period oscillations, two events in
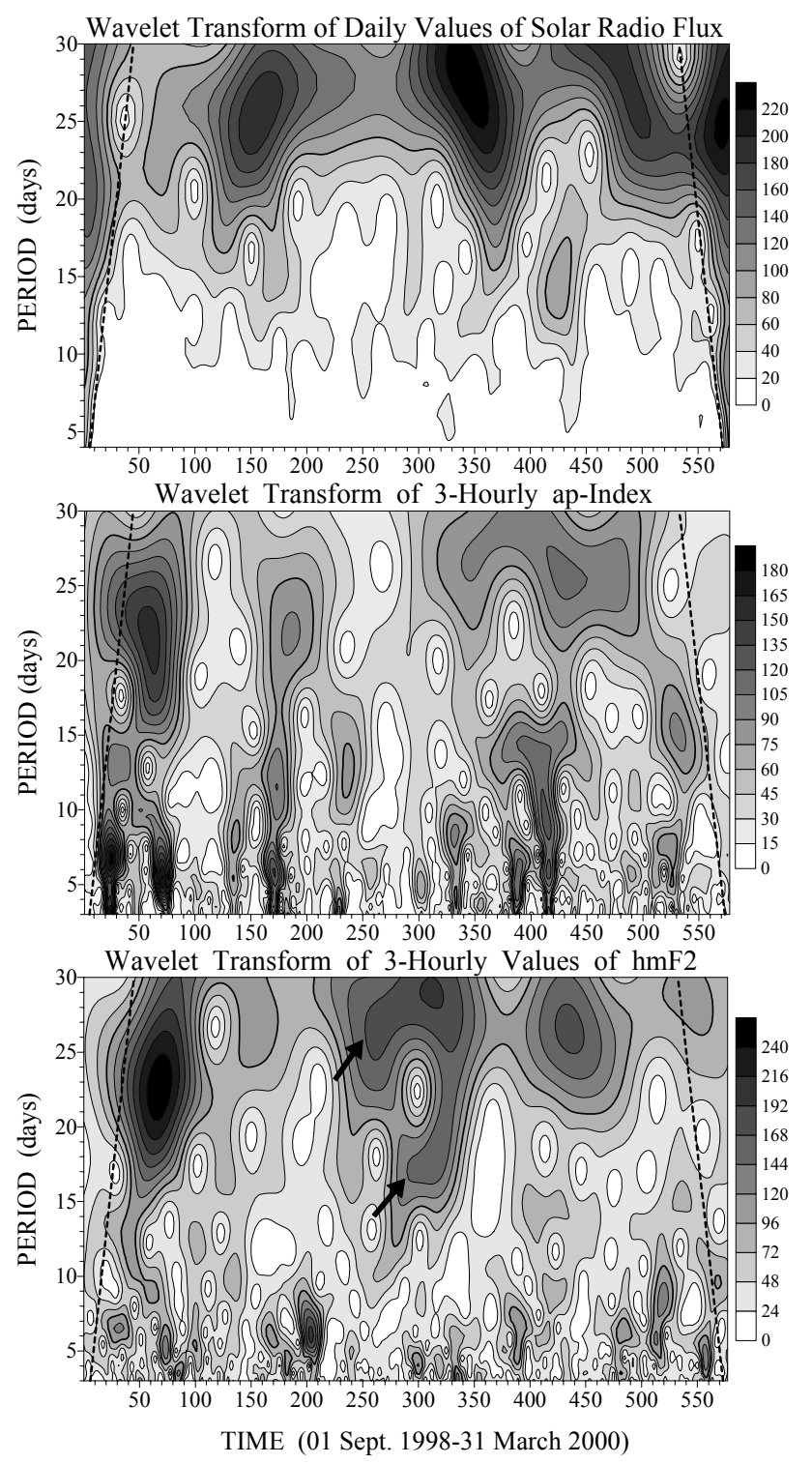

Fig. 1. Wavelet spectra of the solar radio flux F10.7 (upper plot), the geomagnetic $A_{p}$-index (middle) and the maximum height of the F2-layer over Millstone Hill (bottom) in the period range 3-30 days. The thick dashed lines indicate the regions where edge effects become important. The thick contour lines represent the $95 \%$ confidence level.

the $h m F 2$ can be distinguished that are not related to the analogous periodicities in the solar and geomagnetic activity. These oscillations are marked by arrows in the wavelet spectrum of the $h m \mathrm{~F} 2$ and they are: (i) $\sim 27$-day oscillation around day number 250 (April and May, 1999), and (ii) 16day oscillation around day number 300 (summer, 1999). We will try to clarify the origin of these long-period disturbances. There is another, short-period $h m \mathrm{~F} 2$ event with 6-7-day variability observed around day 200, that is neither of solar, not of geomagnetic origin. Otherwise, there are very strong 23and 27-day oscillations around day number 70 and 420, respectively, which are most probably related to the similar 

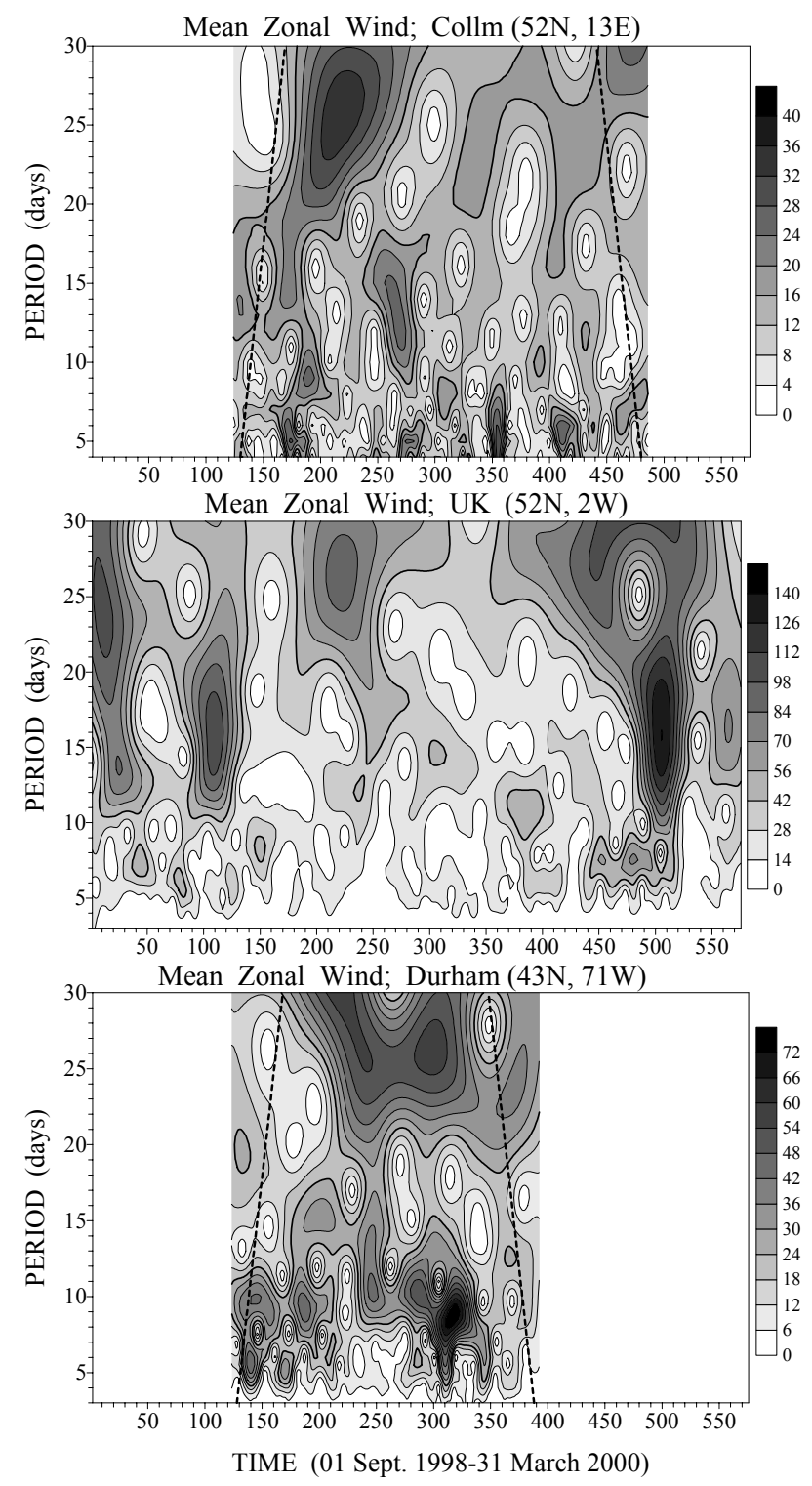

Fig. 2. Wavelet spectra of the zonal winds measured in Collm, Germany (upper plot), in UK (middle) and in Durham, USA (bottom) in the period range 3-30 days.

oscillations present in the geomagnetic activity. Some strong events in the solar and geomagnetic records, however (e.g. days $\sim 150-170$ ), are not reflected in the $h m \mathrm{~F} 2$.

\section{$3.1 \quad$ 27-Day oscillations in spring 1999}

As the 27-day oscillation, evident in the $h m \mathrm{~F} 2$ around day number 250 , is absent in the solar and geomagnetic activity we investigated the neutral wind measured by the meteor radar at Durham. According to Luo et al. (2001) these oscillations are stronger in the zonal component of the neutral wind. Figure 2 shows the wavelet transform of the mean zonal wind at Durham (bottom plot). Because of equipment problems the neutral wind measurements at Durham are available only in the interval 1 January - 30 September 1999.

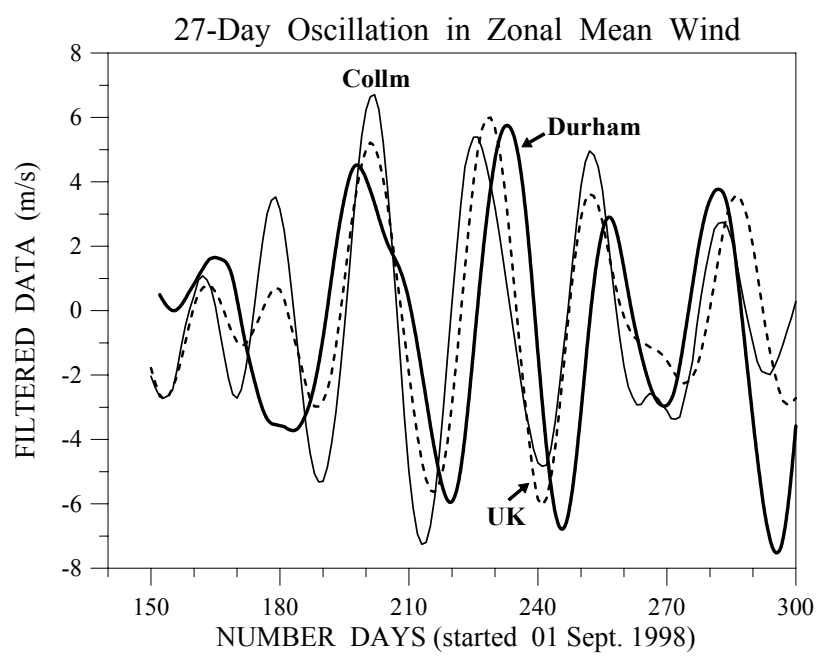

Fig. 3. The band-pass filtered zonal mean winds measured in Durham (thick solid line), Collm (thin solid line) and UK (dashed line). The filter is centred at period of 27 days.

This interval, however, includes the entire 27-day event that we investigate. There is very strong $\sim 27$-day oscillation in the zonal wind simultaneously present with that in the ionosphere. Even both maxima of the 27-day event around days 250 and 300 are evident in the plots of $h m \mathrm{~F} 2$ and the zonal wind at Durham. Figure 2 (bottom plot) also displays wind oscillations at periods below $\sim 10-12$ days that are not reflected in $h m F 2$. (These periods are of non-solar origin according to Fig. 1, because F10.7 does not display any oscillation at periods below 12 days.) However, dynamic forcing of the thermosphere-ionosphere system from below is possible only if there is a global-scale oscillation observed in the MLT region. To determine whether the 27-day oscillation, or those with periods below 10-12 days, observed in the zonal wind at Durham are global-scale events, we have to use some additional neutral wind data. Accordingly, hourly data from the meteor radar at $\mathrm{UK}\left(52^{\circ} \mathrm{N}, 2^{\circ} \mathrm{W}\right)$ and daily data from the $L F$ drift measurements at Collm $\left(52^{\circ} \mathrm{N}, 13^{\circ} \mathrm{E}\right)$ were used. The wavelet spectra of the neutral zonal wind at these additional stations are also shown in Fig. 2, as the upper plot represents the result for Collm and the middle plot - for UK. It is evident that the 27-day oscillation is a global-scale event, while the oscillations with periods below 10-12 days are observed mainly in Durham. (The 7-8-day oscillation around day 190 is only observed over Durham and Collm, but not over UK, so we will not investigate it in detail.) The 27-day oscillation observed over Europe however, has shorter duration (only between day numbers 170 and 300) than that over North America. In the latter case there is the second amplitude maximum around day number 300 similar to the 27-day oscillation present in the $h m \mathrm{~F} 2$ over Millstone Hill. To obtain some information about the real amplitudes of the 27-day oscillation present in the zonal wind measured in these three stations we applied the band-pass filter centred at a period of 27 days and the results are shown in Fig. 3. The global- 

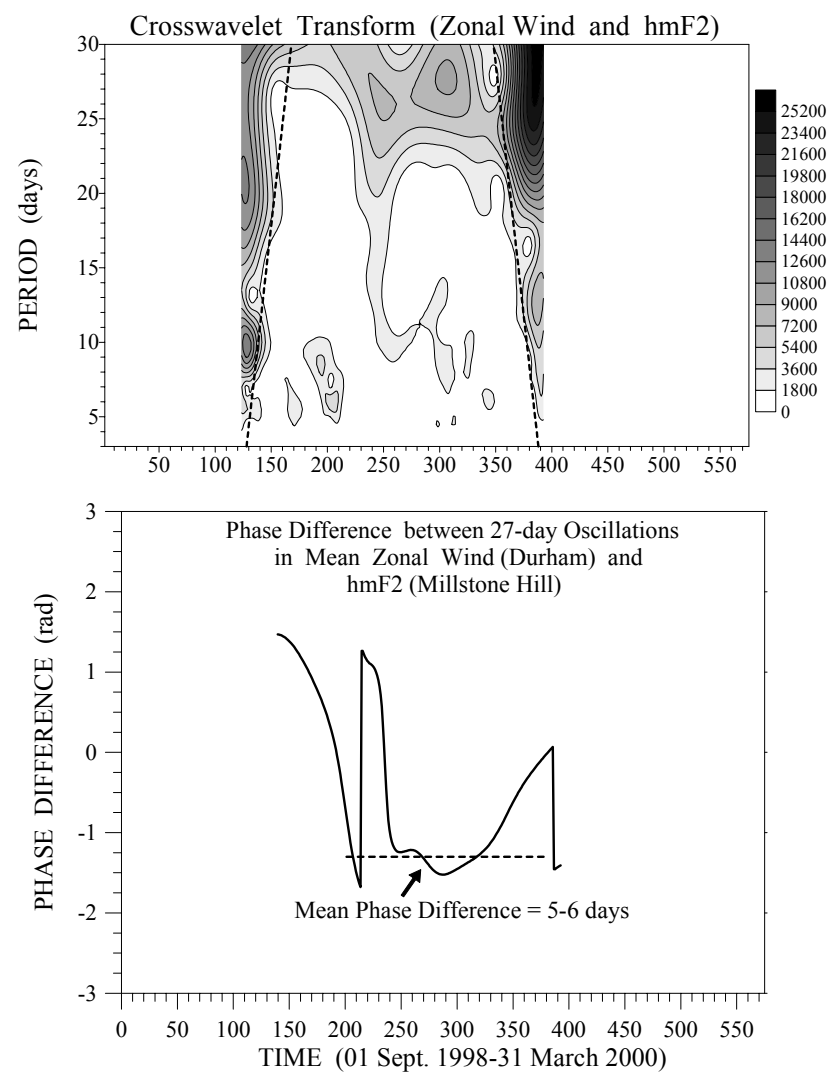

Fig. 4. Cross wavelet transform between the zonal mean wind at Durham and $h m \mathrm{~F} 2$ in Millstone Hill. The upper plot shows the power spectrum of the simultaneously existing oscillations in both time series, while the bottom plot indicates the phase difference between the 27-day oscillations observed in spring/early summer 1999.

scale character of this oscillation is clearly evident. Its amplitude is about $8 \mathrm{~m} / \mathrm{s}$. Likewise, there is a hint of some westward direction of propagation. Using the least squares best fit method applied to the whole interval shown in Fig. 3 (between day number 150 and 300) the calculated zonal wave number is 0.56 . When this best fit method is applied only to the interval between day number 180 and 280, where three cycles are very well outlined, the result is 0.81 , very close to 1 . Therefore, we can accept that the global-scale 27-day oscillation in the zonal wind of the MLT region has westward direction of propagation with zonal wave number 1 . To demonstrate the simultaneous presence of the 27-day oscillations in the neutral wind at Durham and in the ionospheric $h m \mathrm{~F} 2$ parameter we performed the cross-wavelet transform between both time series. The obtained result is shown in Fig. 4. The upper plot shows the power spectrum where two clear maxima around 27 days are evident between days 230 and 340 and that indicate the simultaneous presence of these oscillations in the neutral MLT zonal wind at Durham and in the maximum height of the ionosphere F2-layer at Millstone Hill. The lower plot shows the phase difference between the above mention oscillations. The time delay between the os-
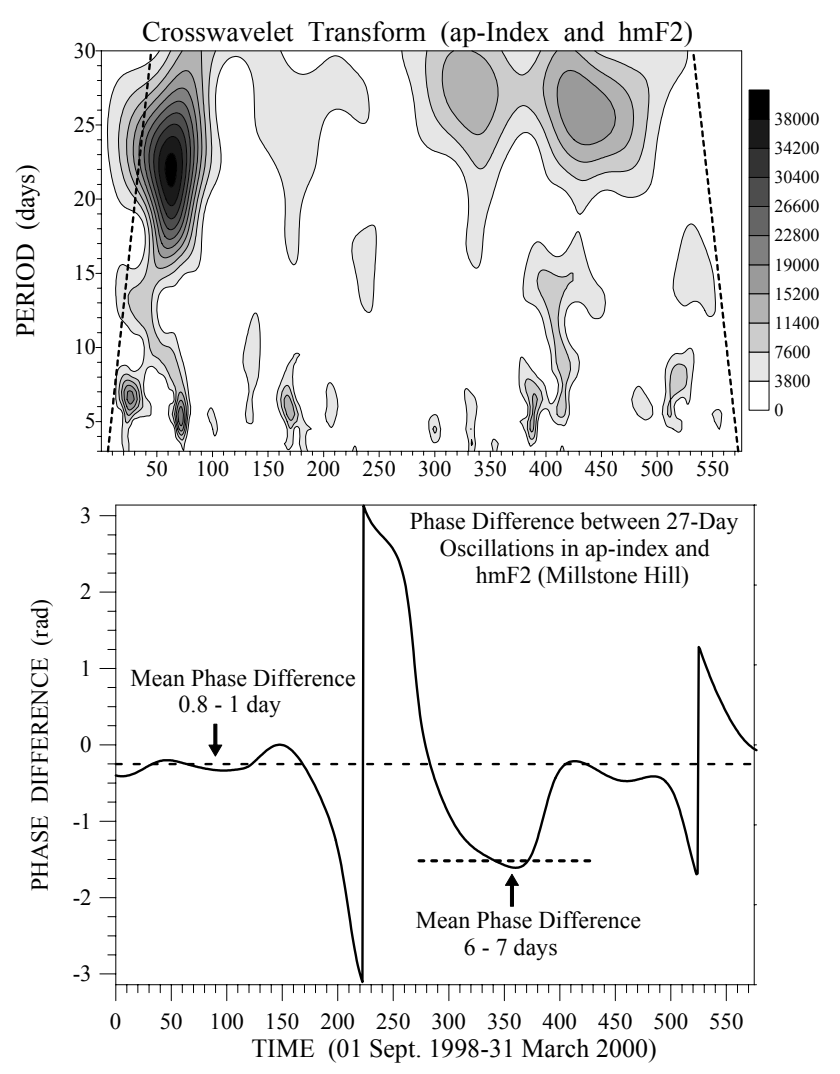

Fig. 5. The same as Fig. 5, but between the geomagnetic $A_{p}$-index and $h m \mathrm{~F} 2$.

cillation in the ionosphere and the one in the zonal MLT wind is 5-6 days. This demonstrates that the 27-day oscillation is first evident in the zonal wind and the response of the ionosphere follows 5-6 days later. The upper plot of Fig. 4 shows also a maximum between 6-8 days around days 190-200. It could be a result from the simultaneous presence of the 7 8-day oscillation evident in the zonal wind at Durham (and Collm, but not at UK) and in the $h m \mathrm{~F} 2$ at Millstone Hill.

To determine the relationship between the oscillations in the geomagnetic activity and those in the ionosphere $h m \mathrm{~F} 2$ parameter we applied the cross-wavelet transform to the respective time series. The result is shown in Fig. 5. The upper plot shows three events simultaneously observed in the $A_{p}$-index and in the $h m \mathrm{~F} 2$. These are a $\sim 23$-day wave around day number 70, and two 27-day oscillations around day numbers 330 and 430 . The phase difference in the first and the third event is about $0.8-1$ day. This means that if the geomagnetic activity is a reason for these oscillations, the response time of the ionosphere is less than one day, which is frequently observed (Prölss, 1995). The empirical model recently created by Kutiev and Mukhtarov (2001), that describes the variations of midlatitude F-region ionisation induced by geomagnetic activity, shows that the average response of the ionosphere to geomagnetic forcing is delayed with a time constant of about $18 \mathrm{~h}$. Therefore, the observed 23- and 27-day oscillations in the ionospheric $h m \mathrm{~F} 2$ param- 

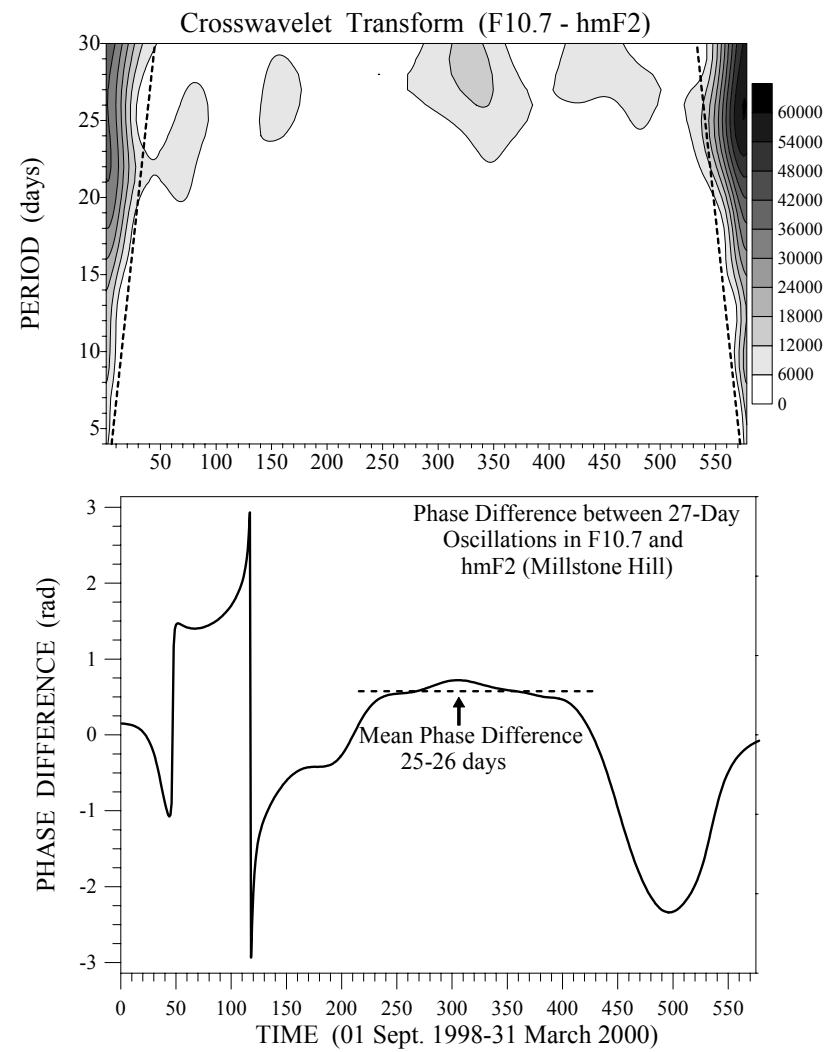

Fig. 6. The same as Fig. 5, but between the solar radio flux F10.7 and $h m \mathrm{~F} 2$.

eter are most probably generated by the geomagnetic activity. However, a problem arises from the second 27-day event (around day number 330), where the phase difference is more than 6-7 days. Usually the geomagnetic response is rather fast, not after 6 or more days. Consequently, this 27-day oscillation in the ionosphere is most probably not related to the geomagnetic activity.

To determine the relationship between the oscillations in the solar activity and those in the ionospheric $h m \mathrm{~F} 2$ parameter we apply the cross-wavelet transform to the respective time series. The result is shown in Fig. 6. There is only a slight maximum with period 27-28 days around day number 320-330. However, the phase difference is positive and it means that the 27-day oscillation in the $h m \mathrm{~F} 2$ appears more than 2 days ahead of that in the solar radio flux F10.7. Alternatively, it can mean that the 27-day oscillation in the ionosphere is delayed more than 25 days with respect to that in the F10.7. Such a long delay between both oscillations is impossible, so the solar radio flux F10.7 probably does not generate this oscillation in the ionosphere.

To demonstrate more clearly the relationship between the 27-day oscillations observed in the $h m \mathrm{~F} 2$ from one side and those in the zonal wind at Durham, the geomagnetic $A_{p^{-}}$ index and the solar radio flux F10.7 from the other side during spring/summer 1999, we investigate the filtered data of the above mentioned parameters. The comparison between the 27-day filtered zonal wind at Durham (dashed line) and
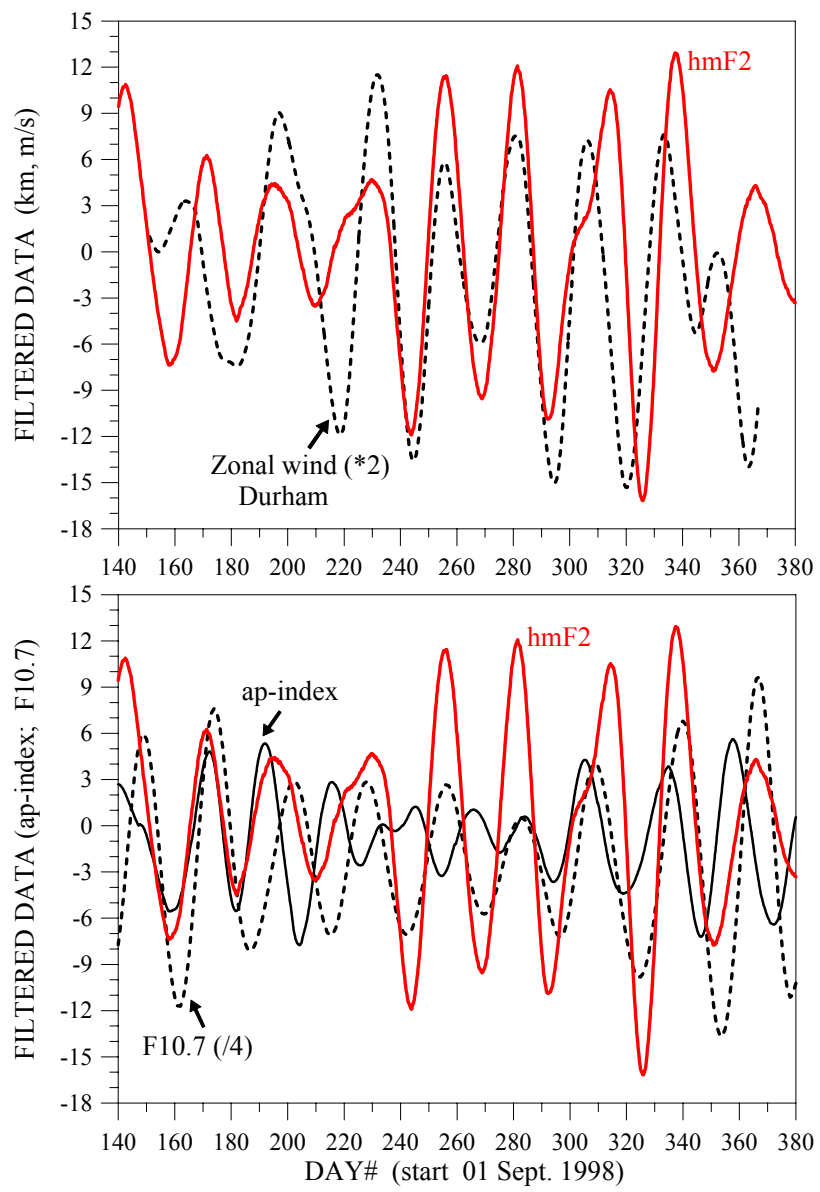

Fig. 7. The 27-day filtered zonal wind data at Durham (black dashed line) and $h m \mathrm{~F} 2$ at Millstone Hill (red line) observed in the interval between day numbers 140 and 380 (shown in the upper plot) and the 27-day filtered $A p$-index (black solid line), F10.7 (black dashed line) and $h m \mathrm{~F} 2$ (red line) in the same time interval (lower plot).

the $h m \mathrm{~F} 2$ (red line) is shown on the upper plot of Fig. 7. It is evident the simultaneous amplification of the 27-day oscillations in both parameters and their synchronous behaviour between days 220 and 340 . The oscillation in the zonal wind generally leads that in the $h m \mathrm{~F} 2$, especially after day number 280. In the bottom plot of the same figure there is a comparison between the 27-day filtered data for the $A_{p}$-index (solid line) and F10.7 (dashed line) with that of the $h m \mathrm{~F} 2$ (red line). It is evident that when the 27-day oscillation in the $h m \mathrm{~F} 2$ is amplified (after day number 220) this oscillation is absent in the $A_{p}$-index and in the F10.7 also. So, the 27-day oscillation in the $h m \mathrm{~F} 2$ evident between day number 220 and 300 is surely related to the 27 -day variability in the zonal MLT region wind. After day number 280-300 however, the 27-day oscillation in the geomagnetic activity, as well as in the solar radio flux, starts to amplify. However, the 27-day oscillation in the zonal wind at Durham is still very strong until day number 340 after which it disappears. We point out that the 27-day oscillation in the $h m \mathrm{~F} 2$ disappears also around day $340-350$, nevertheless that the same oscillations 
in the $A_{p}$-index and in the F10.7 continue to intensify. To be more confident that the 27-day variability in the geomagnetic activity and in the solar radio flux evident after day number 300 are not responsible for the same oscillation in the $h m \mathrm{~F} 2$, we perform cross correlation analysis between $A_{p}$-index and $h m \mathrm{~F} 2$ and between $\mathrm{F} 10.7$ and $h m \mathrm{~F} 2$ for the time interval between days 280 and 380 (see bottom plot of Fig. 7). The results of this analysis support the results from cross wavelet analysis, shown in Figs. 5 and 6. The 27-day oscillation in the $A_{p}$-index is 6 days ahead of that in the $h m \mathrm{~F} 2$ and the same oscillation in the F10.7 is 1.5 days behind that in the $h m \mathrm{~F} 2$.

In this study we take F10.7 as a proxy for the solar extreme ultraviolet (EUV) radiation that produces the F-layer ionisation. According to Balan et al. (1993), F10.7 is a satisfactory indicator for long-term variations (year-to-year, possibly month-to-month) and probably not so good at daily time scale, especially during high solar activity.

The cross wavelet and cross correlation analysis performed on the three pairs of data set shows that the 23and 27-day oscillations in the ionosphere evident around day number 70 and 430 are probably generated by the geomagnetic activity, while the 27-day oscillations with maxima around day number 250 and 320 are probably generated by the similar global scale oscillations present in the zonal MLT region wind.

How can the PW oscillations originating in the middle atmosphere influence the thermosphere-ionosphere system? In Pancheva and Lysenko (1988) two possible mechanisms were discussed. One of them is valid mainly to the quasi2-day oscillations and the other, the ionospheric wind dynamo, involves the PW neutral wind motion to induce electric fields. These electric fields could modulate the height, or plasma density, of the ionospheric F-region. However, the numerical model created by Chen (1992) suggests that the wind magnitudes have to be on the order of a few tens of $\mathrm{m} / \mathrm{s}$ in order to produce the electrodynamic effects inferred from observations. In our case, the observed amplitudes of $8 \mathrm{~m} / \mathrm{s}$ are not strong enough, so, according to the numerical results, the global-scale 27-day oscillation in the zonal wind would probably not be able to generate electrodynamic effects. But our observations support the suggestion that the variability of the MLT zonal wind most probably generates the 27-day oscillation in the ionosphere. Another mechanism, which in general contributes to the upward propagation of planetary wave type oscillations into the F2-region, is modulation of upward propagating tides by planetary waves in the lower (lowest) thermosphere, as supported by experimental results (Lastovicka and Sauli, 1999), as well as by modelling (Müller-Wodarg, 1998).

\subsection{6-Day oscillation in summer 1999}

Figure 1 shows the 16-18-day oscillation in the ionosphere around day number 300 , that is spread over summer months of 1999. There is no similar oscillation in the solar and/or in the geomagnetic activity. Figure 2 shows only slight signature of 14-15-day wave during this time interval in the
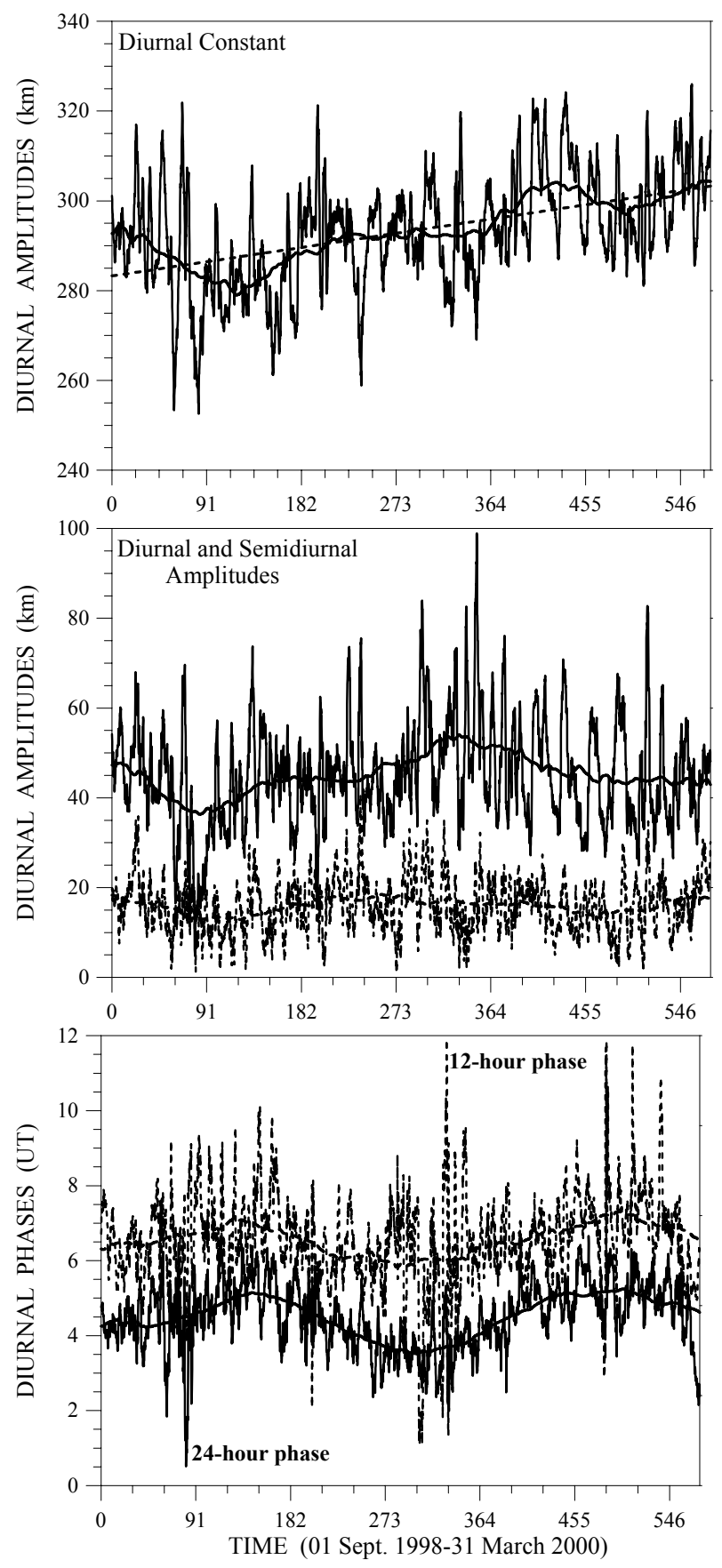

Fig. 8. Variability of the diurnal components of $h m \mathrm{~F} 2$ : the upper plot describes the diurnal mean, the middle plot shows the amplitudes of 24-h (solid line) and 12-h (dashed line) harmonics and the bottom plot shows their phases. The thick solid or dashed lines in these plots describe the seasonal courses of these diurnal components obtained as the 3-month running mean.

neutral wind above Europe and about 12-day wave above Durham. During June-August 1999 a PSMOS (Planetary Scale Mesopause Observing System) MLT radar campaign was conducted and the basic aim of this campaign was to study the tidal variability. 23 MLT radars from Arctic to Antarctic latitudes participated in this campaign and they 

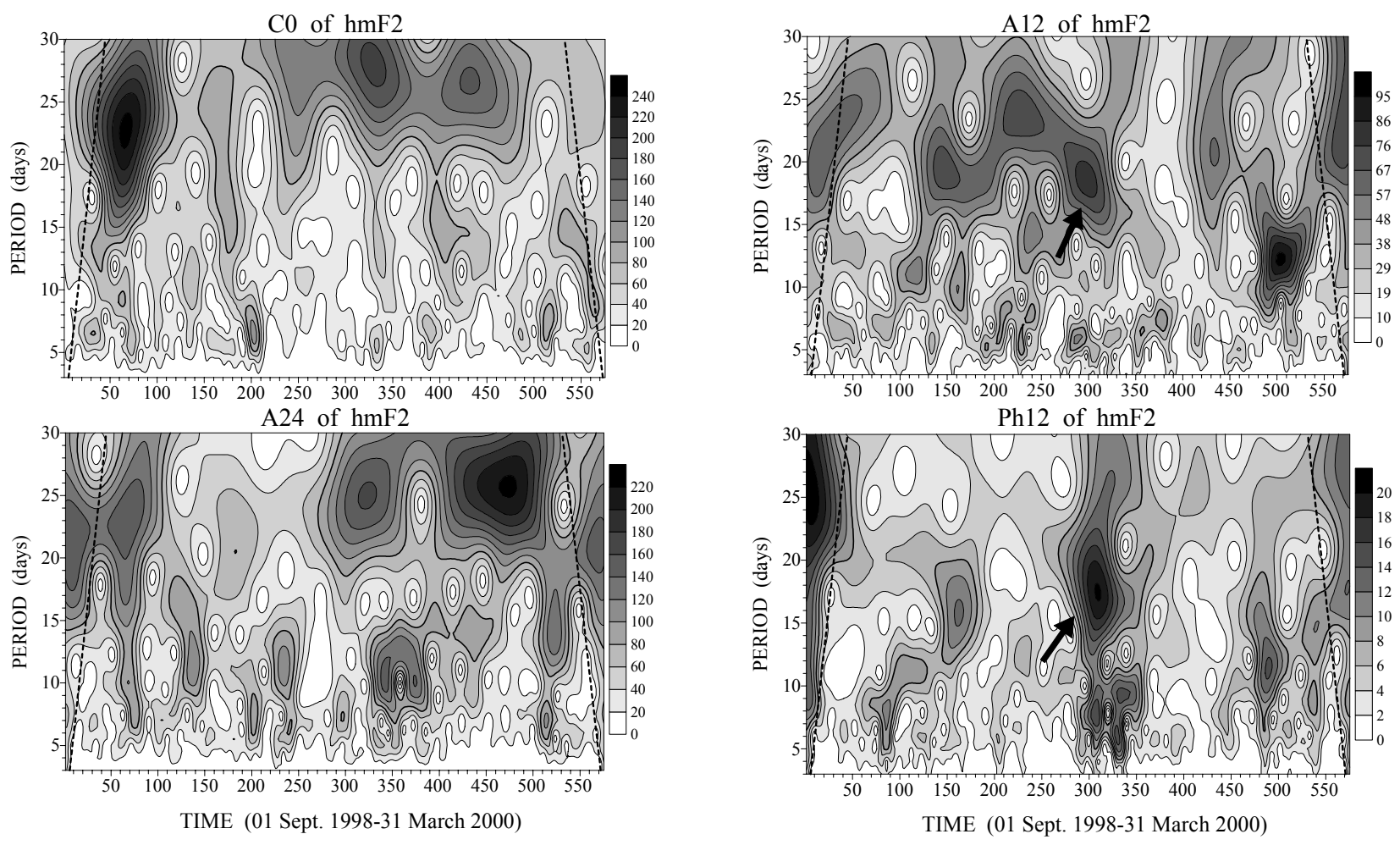

Fig. 9. The wavelet spectra of the diurnal mean (upper left plot), the amplitude of 24- (lower left plot) and 12-h (upper right plot) periodicities of the $h m \mathrm{~F} 2$ and the phase of the 12-h periodicity of the $h m \mathrm{~F} 2$ (lower right plot) in the period range 3-30 days.

have provided knowledge of tidal winds, their amplitudes and phases, for comprehensive ranges of latitudes (equator to poles) with monthly (and higher) resolution. This campaign showed a weak 16-day wave mainly in the meridional component of the neutral wind, but very strong 16-day modulation of the semidiurnal tide. This strong 16-day tidal modulation, with mean amplitude $7-8 \mathrm{~m} / \mathrm{s}$, is evident in both tidal components, suggesting a non-linear interaction with PW of that period to be responsible (Pancheva et al., 2002).

It is known that usually the PWs are not able to penetrate above $120 \mathrm{~km}$, so their direct influence on the ionosphere variability is questionable. The numerical study of the 16day wave (Forbes et al., 1995) showed also that this wave does not favour significant direct penetration into the dynamo region. The semidiurnal tide generated in the middle atmosphere and the troposphere by the absorption of solar radiation by ozone and water vapour, propagates vertically upward and participates in the dynamo generation of electric fields at higher levels. Forbes (1996) suggested that PWs could modulate upward propagating tides and through them to mediate the PW signatures in the ionosphere.

If we assume that the observed 16-day oscillation in the ionospheric $h m \mathrm{~F} 2$ parameter could be generated by the modulated MLT region semidiurnal tide, then probably the semidiurnal periodicity of the $h m \mathrm{~F} 2$ has to be affected. In order to study the variability of the diurnal components of $h m \mathrm{~F} 2$ we decompose it to the diurnal mean and 24-, 12- and 8-h harmonics. They are obtained on the basis of a 3-day time segment that is moving through the time series each $3 \mathrm{~h}$. Figure 8 shows the variations of the diurnal components, as the upper plot describes the diurnal mean, the middle plot shows the amplitudes of 24- (solid) and 12-h (dashed) harmonics and the lower plot shows their phases. The thick solid or dashed lines in these figures describe the seasonal courses of these components obtained as the 3-month running mean. The diurnal components of the $h m \mathrm{~F} 2$ have well expressed seasonal behaviour with clearly depicted shortterm variability. Figure 9 shows the wavelet transform of the diurnal mean (left upper plot) and the amplitudes of 24- (left bottom) and 12-h harmonics (right upper). It is evident that around day number 300 , when the $h m \mathrm{~F} 2$ indicates 16-day oscillation (Fig. 1), only the amplitude of the 12-hour harmonic demonstrates similar disturbance (it is shown by arrow). Figure 9 also shows the wavelet transform of the phase of the 12-h harmonic (right bottom plot) and there a strong, visible 16-day oscillation (shown by an arrow). This result probably indicates, that if the modulated semidiurnal tide mediates the PW signature in the ionosphere, this PW oscillation has to be best expressed in the 12-h periodicity of the ionosphere.

In addition to the strong 16-day peak in the wavelet spectrum of the amplitude of the 12-h $h m \mathrm{~F} 2$ harmonic shown in the Fig. 10 (middle plot), there are also: (i) a 19-20-day peak around day number 150 , (ii) a 24-day peak around day number 230, and (iii) an 11-day peak around day number 500 . The wavelet spectrum of the phase of the 12-h harmonic (Fig. 10, bottom plot) indicates some additional variability 

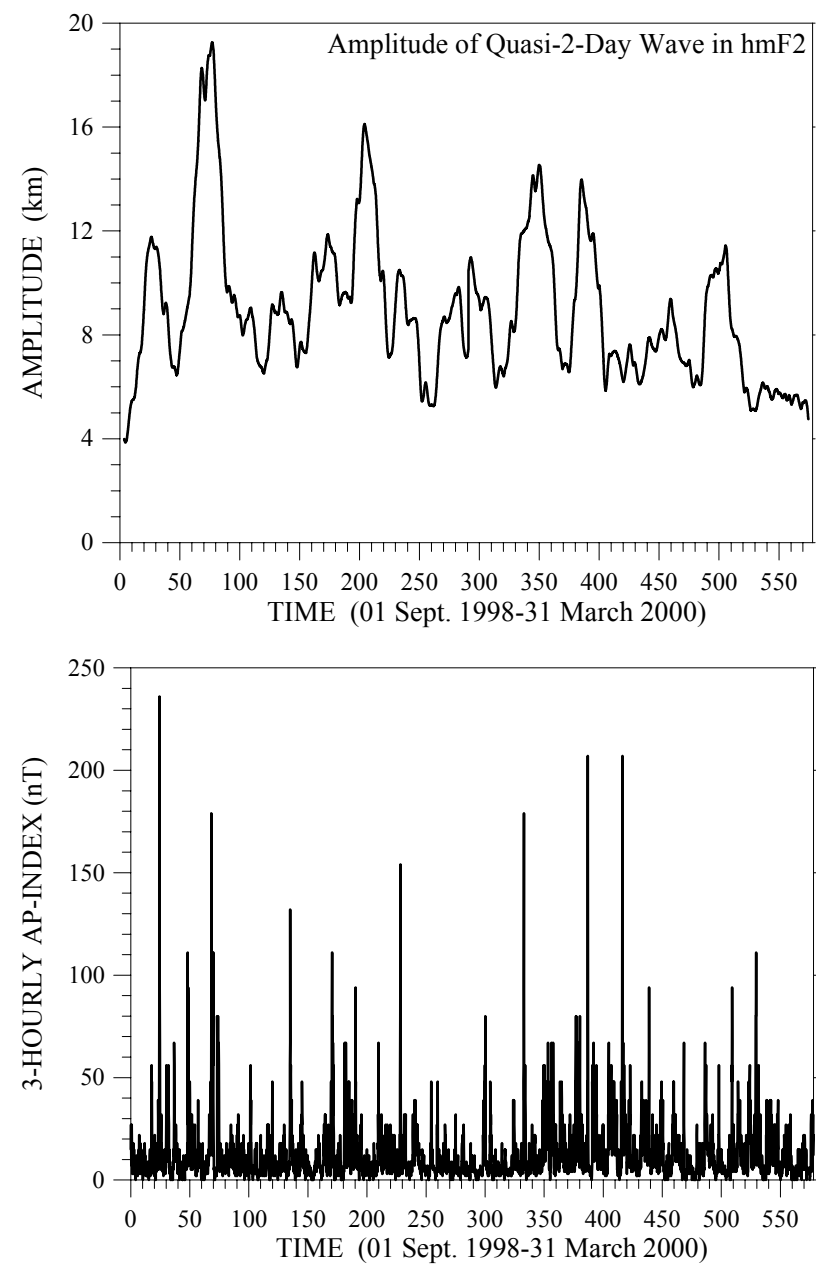

Fig. 10. The temporal variation of the instantaneous amplitudes of the QTD oscillations in the $h m \mathrm{~F} 2$ (upper plot), obtained by the complex demodulation method, and the 3-hourly geomagnetic $A_{p^{-}}$ index shown on the bottom plot.

as: (i) a 15-day oscillation around day number 150 (but not 19-20 days as in the amplitude), (ii) there is no oscillation similar to the 24-day peak in the amplitude of the 12-h $h m \mathrm{~F} 2$ harmonic around day number 230, and (iii) an 11-day peak around day number 490-500. Therefore, the same oscillation observed simultaneously in the amplitude and in the phase of the 12-h hmF2 harmonic is only an 11-day feature centred around day number 500 . Some variability at this time is evident also in the wavelet spectrum of the $h m \mathrm{~F} 2$, but the mean period is about 9-10 days. Unfortunately, we have no neutral wind measurements at Durham and Collm during this time interval, so we have no information about the global-scale semidiurnal tidal variability that could be responsible for the 11-day oscillation evident in the amplitude and in the phase of the 12-h $h m \mathrm{~F} 2$ periodicity.

\subsection{Quasi-2-Day oscillations during equinoxes}

There have been several papers, which delineate quasi-2-day (QTD) oscillations in the ionosphere (Pancheva and Lysenko,
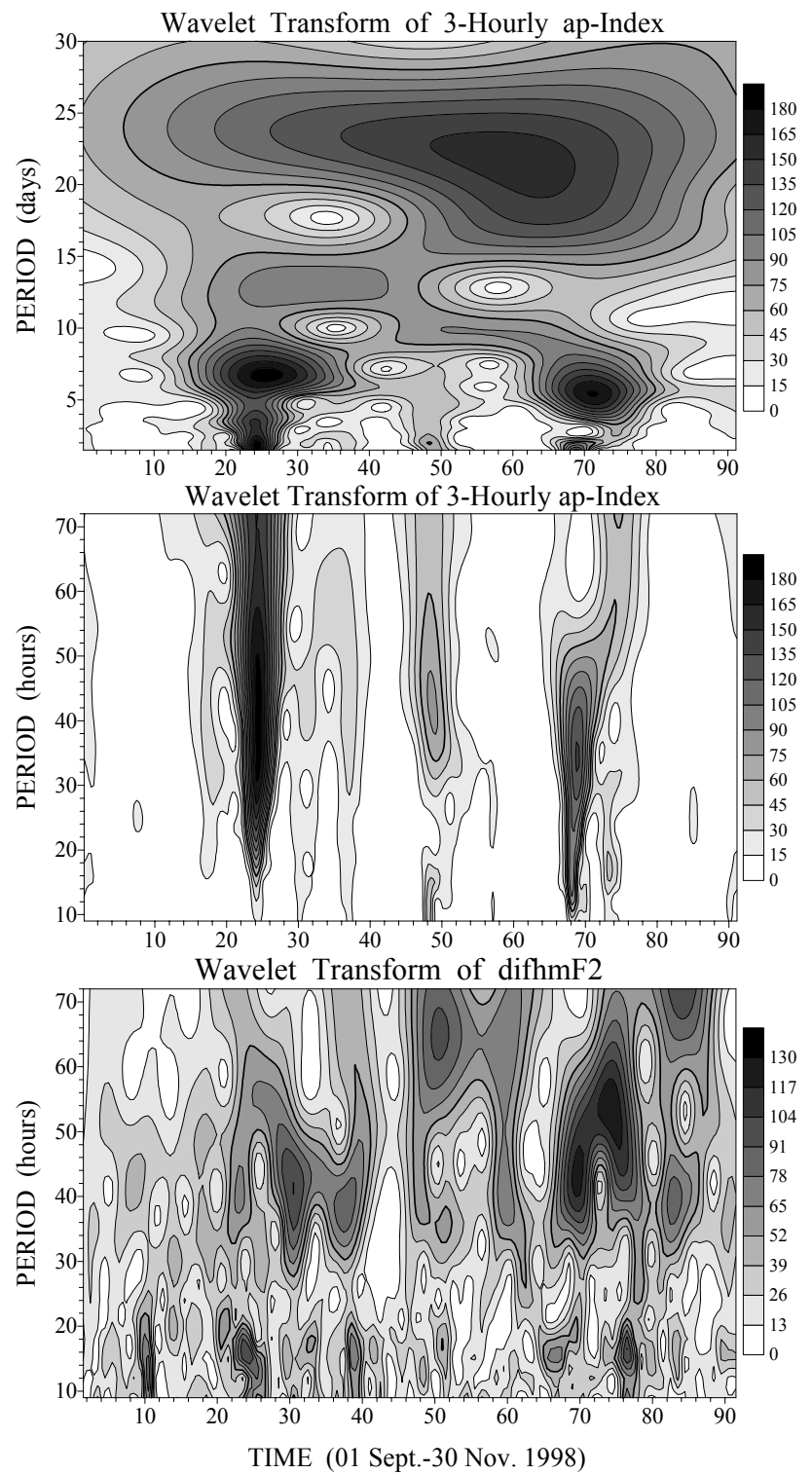

Fig. 11. Wavelet transform of the geomagnetic $A_{p}$-index in the period range 1.5-30 days (upper plot), the wavelet transform of the same parameter, but in the period range 8-72 h (middle) and wavelet transform of the difference between the hourly data and the reference diurnal course of the $h m \mathrm{~F} 2$ (residual of $h m \mathrm{~F} 2$ ) in the period range $8-72 \mathrm{~h}$ (bottom) for the time interval 1 September -30 November 1998.

1988; Pancheva et al., 1994; Apostolov et al., 1995; Altadill et al., 1997; Forbes and Zhang, 1997; Forbes et al., 1997). Some of these are statistical studies involving the spectral analysis of multiyear data sets from specific ionosonde stations and the others represent "case studies" wherein it was attempted to relate the F-region observation with the QTD wind oscillations in the MLT region. However, there is a significant discrepancy between the zonal structures of the QTD oscillations in the MLT region (usually with zonal wave numbers 3 and 4) and those observed in the ionosphere (mainly zonal wave number 1 , or a stationary oscillation with inde- 

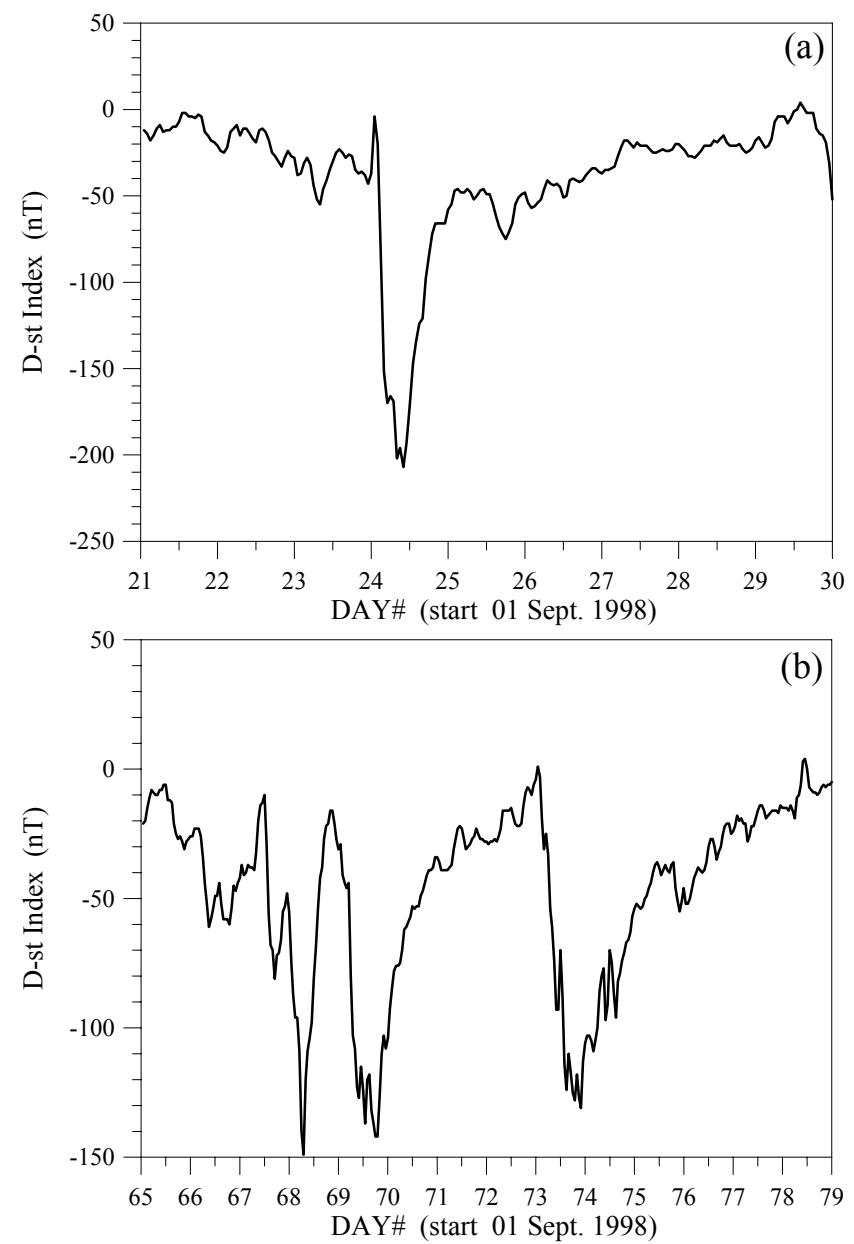

Fig. 12. Description of the geomagnetic storms in: (a) September 1998 and (b) in November 1998 by hourly $D_{s t}$-index

terminable zonal wave number). It was shown that the QTD oscillations are quite regular disturbances of the summer Fregion with typical amplitudes for $f_{o} \mathrm{~F} 2$ in the range 0.4 $1.0 \mathrm{MHz}$ and for $h m \mathrm{~F} 2$ in the range of $8-16 \mathrm{~km}$. Apostolov et al. (1995) and Altadill et al. (1997) showed that the average annual variation of the amplitudes of the QTD oscillation in the $f_{o} \mathrm{~F} 2$ is modulated by the semiannual geomagnetic wave. This interesting result put a question why during the high geomagnetic activity (mostly during the equinoxes) we observe higher QTD oscillation activity in the ionosphere F-region.

We use this "case study" to investigate in detail the QTD oscillations in the $h m \mathrm{~F} 2$, especially during the equinoxes, when the geomagnetic activity is high. As the QTD oscillations are short-period oscillations we will study them using the difference between the hourly data and the reference diurnal course, composed by diurnal mean and 24-, 12- and 8-h harmonics, obtained by using sliding 3-day time segments. To evaluate the temporal variation of the amplitudes of the QTD oscillations, the method of complex demodulation (Bloomfield, 1976) was applied. An effective band-pass filter was used with limits from 40 to $58 \mathrm{~h}$ for the 48 -h de-
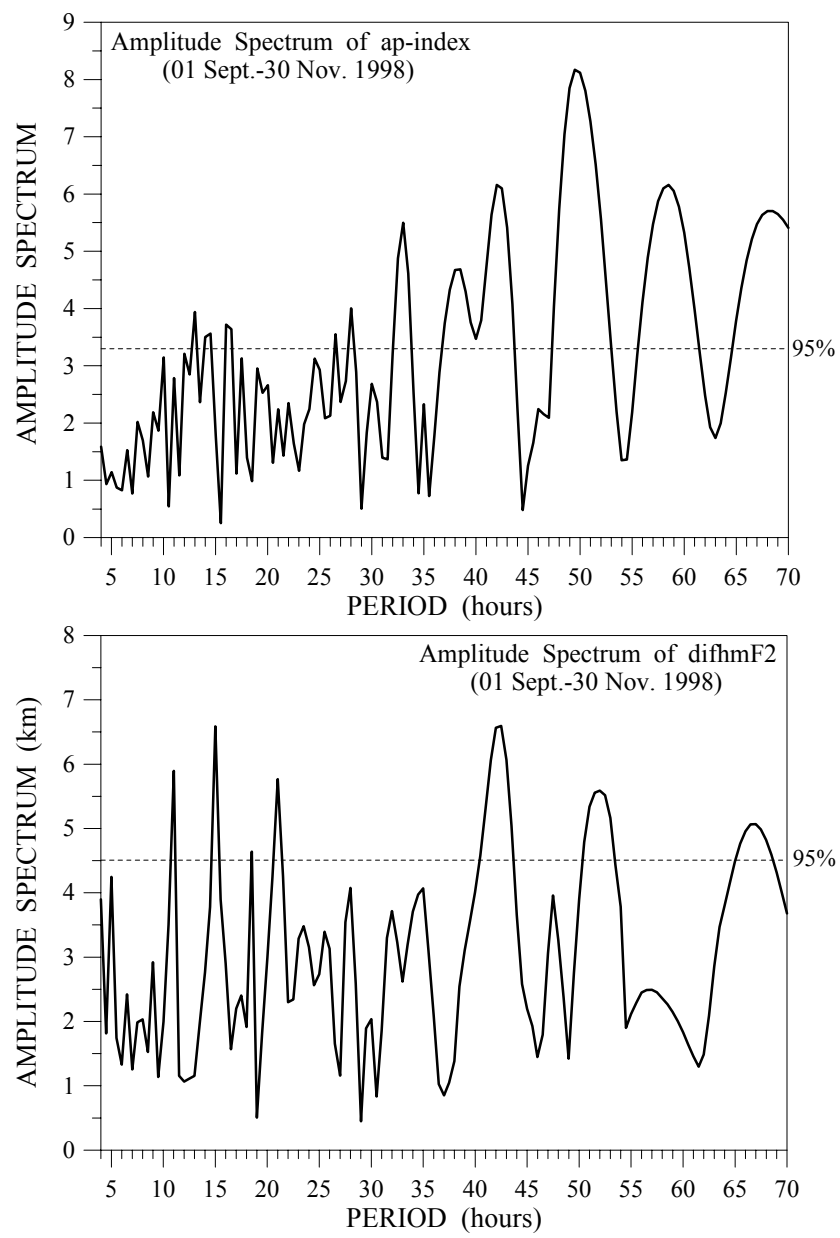

Fig. 13. Amplitude spectra of the geomagnetic $A_{p}$-index (upper plot) and of the residual of $h m \mathrm{~F} 2$ (bottom) in the period range 4$70 \mathrm{~h}$ obtained by the correloperiodogram analysis. The $95 \%$ confidence level is shown by dashed line.

modulation period. Figure 10 shows the temporal variation of the instantaneous amplitudes of the QTD oscillations in the $h m \mathrm{~F} 2$ (upper plot) and the 3-hourly $A_{p}$-index in the lower plot. There is positive relation between the high geomagnetic activity and the increase of the amplitudes of the QTD oscillations, especially well evident in the fall of 1998 and spring of 1999. As the strongest QTD oscillations in $h m \mathrm{~F} 2$ are observed in the fall of 1998 we will study this seasonal interval in detail.

Figure 11 shows the wavelet transform of the 3-hourly $A_{p}$-index in the period interval 1.5-30 days (upper plot), the wavelet transform of the same parameter, but in the period range $8-72 \mathrm{~h}$ (middle plot) and the wavelet transform of the difference between the hourly data and the reference diurnal course of $h m \mathrm{~F} 2$ also in the period range $8-72 \mathrm{~h}$ (lower plot) for the time interval 1 September - 30 November 1998. The geomagnetic disturbances are clearly depicted in the upper and middle plots and they are centred at day number 25 and 69. The description of these geomagnetic disturbances 
through the hourly $D_{s t}$-index is shown in Fig. 12. Enhanced QTD oscillations at the days of the main phase of the storms and a few days later are evident in the ionosphere (lower plot of Fig. 11). The QTD oscillations related to the first geomagnetic disturbance have mean periods $\sim 40-42 \mathrm{~h}$ and they are generated at the recovery phase of the geomagnetic disturbance. At the same time the main peak in the $A_{p}$-index is $\sim 50 \mathrm{~h}$ and it is evident during the main phase of the studied disturbances. The QTD oscillations related to the second geomagnetic disturbance are composed of a burst with mean period $42 \mathrm{~h}$ that coincides with the main phase of the storm and a second burst, with mean period $52-53 \mathrm{~h}$, that is generated at the beginning of recovery phase after the third peak in the $D_{s t}$-index (Fig. 12). Figure 13 shows the main spectral peaks that are present in the geomagnetic $A_{p}$-index and in the analysed ionospheric data for the investigated 3month time interval. There are two interesting features: (i) the main peaks in the ionosphere have periods 42 and $52.5 \mathrm{~h}$ and the same peak of $42 \mathrm{~h}$ is evident in the geomagnetic activity also. This suggests that the 42-h QTD oscillation evident in the ionosphere during the main phase of the second geomagnetic storm (at day number 69 of the lower plot of Fig. 12) is probably generated directly by the similar oscillation in the geomagnetic activity; (ii) in addition to the QTD peaks in the ionospheric data, there are also significant peaks, well above the $95 \%$ confidence level, with periods 11,15 and $21 \mathrm{~h}$ (after the 24-, 12- and 8-h diurnal harmonics are removed). Why are these pseudo diurnal harmonics significantly strong during the geomagnetic storm? Fuller-Rowell et al. (1996) and Fuller-Rowell et al. (2000) offered a scenario (Similar to that already suggested by Prölls, 1995) of the global response of the thermosphere-ionosphere system to magnetospheric energy input. This scenario is formulated around the temporal and spatial progress of the "composition bulge", as they called this region, where the gas mean molecular mass number is highest. Namely this composition bulge, driven by the changed prevailing winds and insitu generated tides (Müller-Wodarg et al., 2001) and its own temporal evolution, disturbs the usual diurnal behaviour of the ionosphere. Therefore, the strong pseudo diurnal periodicities evident in the amplitude spectrum of the residual of $h m \mathrm{~F} 2$ during high geomagnetic activity are probably related to the influence of this composition bulge. Figure 14 shows the bispectrum estimate calculated from the residual of $h m \mathrm{~F} 2$. The non-zero points, marked as 1 and 2, represent the triplets $(52.5,21,15)$ hours and $(41.3,15,11)$ hours, respectively. However, Clark and Bergin (1997) pointed out, that the initial two mixing components could be any two of the three frequencies. Therefore, as strong pseudo diurnal periodicities are generated during high geomagnetic activity (Fig. 13), we may assume that 21- and 15-h frequencies interact to generate the QTD oscillation with period 52.5-h and that 15- and 11-h frequencies interact to generate the 41.3$\mathrm{h}$ oscillation. These interactions between the pseudo diurnal harmonics take place in the recovery phase of the geomagnetic storms, as is shown in the bottom plot of Fig. 11.

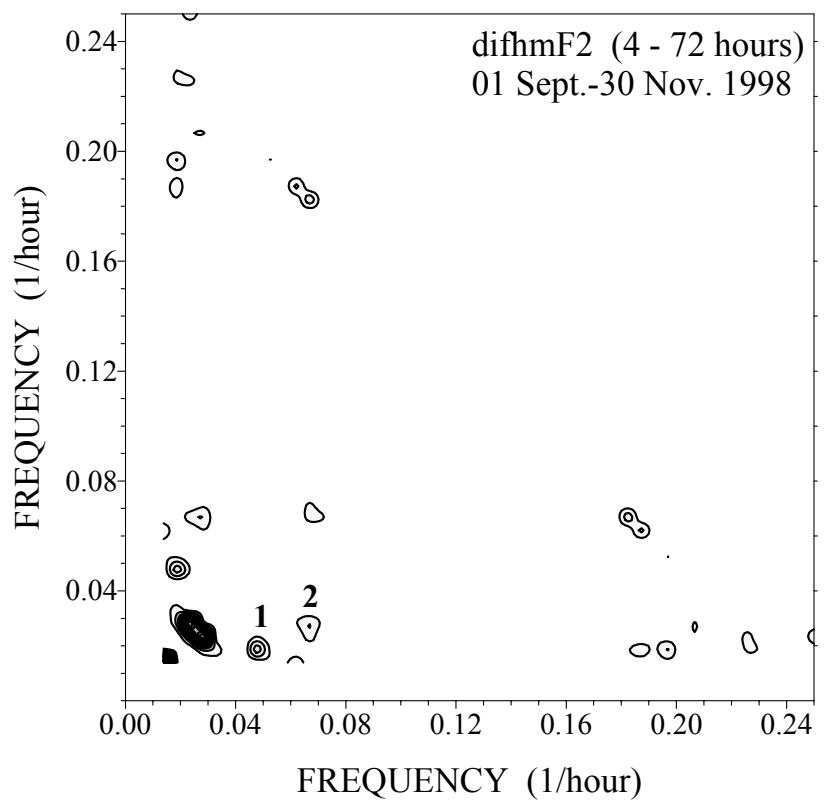

Fig. 14. The contour plot of the magnitude square bispectrum calculated from the residual of the $h m \mathrm{~F} 2$ data in the period interval 4-72h.

\section{Conclusions}

The purpose of the present 'case study' is to investigate the variability in the maximum height of the ionospheric F2layer, $h m \mathrm{~F} 2$, with periods of planetary waves (2-30 days), and to make an attempt to determine their origin. The hourly data of the $h m \mathrm{~F} 2$ above Millstone Hill $\left(42.6^{\circ} \mathrm{N}, 71.5^{\circ} \mathrm{W}\right)$ during 1 September 1998 - 31 March 2000 were analysed to study in detail three types of disturbances: the long-term $27-$ and 16-day oscillations and the short-term quasi-2-day oscillations. The following main results were obtained:

- There were three different 27-day events observed in the $h m \mathrm{~F} 2$ : during autumn of 1998 and 1999 and during spring/early summer of 1999 . Most probably the 27day oscillation observed in the $h m \mathrm{~F} 2$ above Millstone Hill in spring/early summer of 1999 is generated by the global-scale 27-day wave present in the zonal MLT neutral wind. The time delay between the 27-day oscillation in the zonal wind and that in the $h m \mathrm{~F} 2$ is found to be 5-6 days. The 27-day oscillations observed in autumn are generated by the geomagnetic activity. In this case the time delay between the 27-day oscillation in the geomagnetic activity and that in the $h m \mathrm{~F} 2$ is $0.8-1$ day.

- The 16-day oscillation in the $h m \mathrm{~F} 2$ observed during summer 1999 is probably generated by the global scale 16-day modulation of the semidiurnal tide observed in the MLT region during PSMOS campaign in JuneAugust. When the modulated semidiurnal tide mediates the planetary wave signature in the ionosphere, this planetary wave oscillation has to be best expressed in 
the amplitude and in the phase of the 12 -h periodicity of the ionosphere.

- The quasi-2-day activity in the $h m \mathrm{~F} 2$ increases during geomagnetic disturbances. The strong pseudo diurnal periodicities generated during the geomagnetic storms can interact between each other and produce the quasi2-day oscillations in the ionosphere. This mechanism could explain why the average annual variation of the amplitudes of the QTD oscillation in the foF 2 is modulated by the semiannual geomagnetic wave (Apostolov et al., 1995; Altadill et al., 1997). However, the observed QTD oscillation in the ionospheric F-region during summer is generated mainly by the quasi-2-day wave in the neutral wind of the MLT region.

Acknowledgements. Topical Editor M. Lester thanks D. Altadill and another referee for their help in evaluating this paper.

\section{References}

Altadill, D., Apostolov, E. M., and Alberca, L. F.: Some seasonal hemispheric similarities in $f o \mathrm{~F} 2$ quasi-2-day oscillations, J. Geophys. Res., 102, 9737-9739, 1997.

Apostolov, E. M., Altadill, D., and Alberca, L. F.: Characteristics of quasi-2-day oscillations in the foF2 at northern middle latitudes, J. Geophys. Res., 100, 12 163-12 171, 1995.

Apostolov, E. M., Altadill, D., and Hanbaba, R.: Spectral energy contributions of quasi-periodical oscillations (2-35 days) to the variability of $f_{o} \mathrm{~F} 2$, Ann. Geophysicae, 16, 168-175, 1998.

Balan, N., Bailey, G. J., and Jayachandran, B.: Ionospheric evidence for a nonlinear relationship between the solar EUV and $10.7 \mathrm{~cm}$ fluxes during an intense solar cycle, Planet. Space Sci., 41, 141-145, 1993.

Beard, G. A., Mitchell, N. J., Williams, P. J. S., and Kunitake, M.: Non-linear interactions between tides and planetary waves resulting in periodic tidal variability, J. Atmos. Sol.-Terr. Phys., 61, 363-376, 1999.

Bloomfield, P.: Fourier Analysis of Time Series: An Introduction, John Wiley, New York, 1976.

Chen, P. R.: Two-day oscillation of the equatorial ionisation anomaly, J. Geophys. Res., 99, 6343-6357, 1992.

Clark, R. R. and Bergin, J. S.: Bispectral analysis of mesosphere wind, J. Atmos. Sol.-Terr. Phys., 59, 629-639, 1997.

Forbes, J. M., Hagan, M.E., Miyahara, S., Vial, F., Manson, A. H., Meek, C. E., and Portnyagin, Yu.: Quasi-16-day oscillation in the mesosphere and lower thermosphere, J. Geophys. Res., 100, 9149-9164, 1995.

Forbes, J. M.: Planetary waves in the thermosphere-ionosphere system, J. Geomag. Geoelec., 48, 91-98, 1996.

Forbes, J. M. and Zhang, X.: Quasi 2-day oscillation of the ionosphere: A statistical study, J. Atmos. Sol.-Terr. Phys., 59, 10251034, 1997.

Forbes, J. M., Guffee, R., Zhang, X., Fritts, D., Riggin, D., Manson, A., Meek, C., and Vincent, R. A.: Quasi-2-day oscillation of the ionosphere during summer 1992, J. Geophys. Res., 102, 73017305, 1997.

Forbes, J. M., Palo, S. E., and Zhang, X.: Variability of the ionosphere, J. Atmos. Sol.-Terr. Phys., 62, 685-693, 2000.
Foster, J. C., Holt, J. M., Musgrove, R. G., and Evans, D. S.: Ionospheric convection associated with discrete levels of particle precipitation, Geophys. Res. Lett., 13, 656-659, 1986.

Fuller-Rowell, T. J. and Evans, D. S.: Height-integrated Pedersen and Hall conductivity patterns inferred from TIROS-NOAA satellite data, J. Geophys. Res., 92, 7606-7618, 1987.

Fuller-Rowell, T. J., Codrescu, M. V., Moffett, R. J., and Quegan, S.: Response of the thermosphere and ionosphere to geomagnetic storms, J. Geophys. Res., 99, 3893-3914, 1994.

Fuller-Rowell, T. J., Condrescu, M. V., Rishbeth, H., Moffett, R. J., and Quegan, S.: On the seasonal response of the thermosphere and ionosphere to geomagnetic storms, J. Geophys. Res., 101, 2343-2353, 1996.

Fuller-Rowell, T. J., Codrescu, M. V., and Wilkinson, M.: Quantitative modelling of the ionospheric response to geomagnetic activity, Ann. Geophysicae., 18, 766-781, 2000.

Hagan, M. E., Forbes, J. M., and Vial, F.: On modelling migrating solar tides, Geophys. Res. Lett., 22, 893-896, 1995.

Hagan, M. E., Burrage, M. D., Forbes, J. F., J. Hackney, Randel, W. J., and Zhang, X.: GSWM-98: Results for migrating solar tides, J. Geophys. Res., 104, 6813-6828, 1999.

Hagan, M. E., Roble, R. G., and Hackney, J.: Migrating thermospheric tides, J. Geophys. Res., 106, 12 739-12 752, 2001.

Kutiev, I. and Mukhtarov, P.: Modeling of midlatitude F-region response to geomagnetic activity, J. Geophys. Res., 106, $15501-$ 15 509, 2001.

Kopecky, M. and Kuklin, G.: About 11-year variation of the mean life duration of a group sun spots, Issled. Geomagn. Aeronom. Foz. Solntsa, 2, 167, 1971.

Lastovicka, J. and Sauli, P.: Are planetary wave type oscillations in the F2-region caused by planetary wave modulation of upward propagating tides? Adv. Space Res., 24, 1473-1476, 1999.

Luo, Y., Manson, A. H., Meek, C. E., Igarashi, K., and Jacobi, Ch.: Extra long period (20-40 day) oscillations in the mesosphere and lower thermosphere winds: Observations in Canada, Europe and Japan, and considerations of possible solar influences, J. Atmos. Sol.-Terr. Phys., 63, 835-852, 2001.

Miyahara, S. and Wu, D. H.: Effects of solar tides on the zonal mean circulation in the lower thermosphere: Solstice condition, J. Atmos. Terr. Phys., 51, 635-648, 1989.

Müller-Wodarg, I. F. C.: Propagation of planetary waves into the thermosphere and ionosphere - a modelling study, XXIII EGS, Nice, Book of Abstracts, p. C846, 1998.

Müller-Wodarg, I. F. C., Aylward, A. D., and Fuller-Rowell, T. J.: Tidal oscillations in the thermosphere: a theoretical investigation of their sources, J. Atmos. Sol.-Terr. Phys., 63, 899-914, 2001.

Pancheva, D. and Lysenko, I.: Quasi-two-day fluctuations observed in the summer F-region electron maximum, Bulg. Geophys. J., 14(2), 41-51, 1988.

Pancheva D., Schminder, R., and Lastovicka, J.: 27-day fluctuations in the ionospheric D-region, J. Atmos. Terr. Phys., 53, 11451150, 1991.

Pancheva, D., Alberca, L., and de la Morena, B.: Simultaneous observation of the quasi-two-day wave variations in the lower and upper ionosphere over Europe, J. Atmos. Terr. Phys., 56, 4350, 1994

Pancheva, D.: Evidence for non-linear coupling of planetary waves and tides in the lower thermosphere over Bulgaria, J. Atmos. Sol.-Terr. Phys., 62, 115-132, 2000.

Pancheva, D. and Mukhtarov, P.: Wavelet analysis on transient behaviour of tidal amplitude fluctuations observed by meteor radar in the lower thermosphere over Bulgaria, Ann. Geophysicae., 18, 
316-331, 2000.

D. Pancheva, Merzlyakov, E., Mitchell, N. J., Portnyagin, Yu., Manson, A. H., Jacobi, Ch., Meek, C. E., Luo, Y., Clark, R. R., Hocking, W. K., MacDougall, J., Muller, H. G., Kürschner, D., Jones, G. O. L., Vincent, R. A., Reid, I. M., Singer, W., Igarashi, K., Fraser, G. I., Fahrutdinova, A. N., Stepanov, A. M., Poole, L. M. G., Malinga, S. B., Kashcheyev, B. L., and Oleynikov, A. N.: Global scale tidal variability during the PSMOS campaign of June-August 1999 with periods of planetary waves, J. Atmos. Sol.-Terr. Phys., in press, 2002.
Prölss, G. W.: Ionospheric F-region storms, in: Handbook for Atmospheric Electrodynamics, vol. 2, (Ed) Volland, H., CRC Press, Boca Raton, pp. 195-248, 1995.

Reinisch, B.: Modern Ionosonde, in: Modern Ionospheric Science, (Eds) Kohl, H., Rüster, R., and Schlegel, K., EGS, KatlenburgLindau, Germany, pp. 440-458, 1996.

Rishbeth, H. and Mendillo, M.: Patterns of F2-layer variability, J. Atmos. Sol.-Terr. Phys., 63, 1661-1680, 2001.

Torrence, C. and Compo, G.: A practical guide to wavelet analysis, Bull. Amer. Meteor. Soc., 79, 61-78, 1998. 